\title{
Facile and simple preparation of pH-sensitive chitosan-mesoporous silica nanoparticles for future breast cancer treatment
}

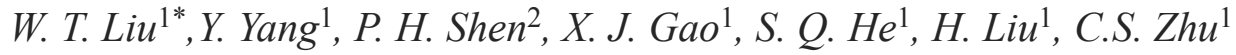 \\ ${ }^{1}$ School of Material Science and Engineering, Zhengzhou University, 450052 Zhengzhou, Henan province, China \\ ${ }^{2}$ The Fifth Affiliated Hospital of Zhengzhou University, 450052 Zhengzhou, Henan province, China
}

Received 26 April 2015; accepted in revised form 8 July 2015

\begin{abstract}
The nanocarrier is linked to the core and shell by hydrogen bond. This drug delivery system represents a smart, biodegradable, and $\mathrm{pH}$-sensitive nanocarrier for breast cancer therapy. These drug nanocarriers were linked by hydrogen bond from $-\mathrm{NH}_{2}$ on chitosan and $-\mathrm{OH}$ on mesoporous silica nanoparticle (MSN). And MSN was prepared by the cetyltrimethyl ammonium bromide (CTAB)-templated method via sol-gel and the loading of ibuprofen (IBU) into the pores of MSN was visualized by coprecipitation which was assessed by Fourier Transform Infrared Spectroscopy (FTIR) and nitrogen adsorption-desorption techniques. The wrapping of chitosan (CS) onto the surface of MSN was demonstrated by FTIR too. When the nanocarriers entered an acidic environment where large quantity cancer cells existed, the chitosan shell swell into loose random coil, exposing the drug and making them easy to be released. The results showed that the IBU could be successfully and effectively loaded into MSN and CS/MSN. The system was pH responsive. Drug release was much higher at $\mathrm{pH} 6.8$ than at 7.4. This drug delivery system will represent a smart and biodegradable $\mathrm{pH}$-responsive nanocarrier for breast cancer.
\end{abstract}

Keywords: smart polymers, chitosan, MSN, pH-sensitive nanoparticles, drug delivery system

\section{Introduction}

For cancer therapy, people have found that drug controlled delivery system [1] could control the release of drugs and significantly reduce the side effects in recent years [2-6]. Moreover, $\mathrm{pH}-$-responsive drug controlled delivery system [7-13] can release drug at certain part of body, because $\mathrm{pH}$ value is different at each part of the human body. The normal body fluid $\mathrm{pH}$ is about 7.4, while the $\mathrm{pH}$ value at cancer cell is approximately 6.8 . Several biodegradable materials, such as chitosan [14], polylactic acid [15], gelatin [16], polycaprolactone [17] and poly-alkyl-cyanoacrylates [18] have been used as intelligent drug delivery systems. In the meanwhile, some inorganic nanoparticles like meso- porous silica (MSN), $\mathrm{Fe}_{3} \mathrm{O}_{4}$, carbon nanotubes, quantum dots [19-22] are also used as drug delivery systems.

MSN has been widely used in biomedical due to its good biocompatibility, non-toxic, tunable pore size, large surface areas and pore volume, modifiable surface, biodegradation, good chemical and thermal stabilities and other advantages [19, 23-26]. But unmodified MSN is not intelligent and has potential toxicity at high dose because of the interactions of surface silanols with cellular membranes [27, 28]. So it is necessary to wrap MSN with biomolecules, so that the system is intelligent and low toxicity [28, 29]. Chitosan has been widely used in intelligent drug delivery system because it has unique properties

\footnotetext{
${ }^{*}$ Corresponding author, e-mail: wtliu@zzu.edu.cn

(C) BME-PT
} 
such as non-toxicity, biocompatibility, biodegradability, and so on [30]. The ionization of large quantities of amino groups on chains of chitosan provides it as a $\mathrm{pH}$-sensitive 'gatekeeper'.

Many polymer-coated and $\mathrm{pH}$-sensitive MSN nanocarriers have been designed, while most of the system add poisonous solvent and the preparation process is complex. In the present work, we have developed a simple and facile approach to prepare an intelligent drug controlled delivery system by hydrogen bonding biopolymer as $\mathrm{pH}$-responsive 'gatekeeper' and inorganic nanoparticles as drug carriers. Meanwhile, the system is sensitive to a narrow $\mathrm{pH}$ range. We described a $\mathrm{pH}$-responsive drug nanocarrier based on MSNs, which was wrapped by chitosan. And drug controlled release was studied at pH 7.4 and 6.8 which used IBU as a model drug.

\section{Experimental section}

\subsection{Materials}

Cetyltrimethylammonium bromide (Tianjin Jinbei Fine Chemical Co., Ltd, China), tetraethyl orthosilicate (TEOS, analytical reagent, Tianjin Fuchen chemical reagent factory, China), mesitylene (Aladdin Industrial Corportion, China), chitosan $\left(\mathrm{CS}, M_{\mathrm{W}}=\right.$ $110000-150000$, Amresco, USA), sodium hydroxide (NaOH, Tianjin DeEn Chemical Co., Ltd, China), n-hexane $\left(\mathrm{C}_{6} \mathrm{H}_{14}\right.$, Tianjin Fengchuan Chemical Co., Ltd, China), ethanol $\left(\mathrm{CH}_{3} \mathrm{CH}_{2} \mathrm{OH}\right.$, Tianjin Fengchuan Chemical Co., Ltd,China), ammonium nitrate $\left(\mathrm{NH}_{4} \mathrm{NO}_{3}\right.$, Tianjin Jinbei Fine Chemical Co., Ltd, China).

\subsection{Characterization}

Fourier transform infrared spectroscopy analysis was performed by using $\mathrm{KBr}$ in the region of 4000$400 \mathrm{~cm}^{-1}$ by Nicolet PROTE/GE/460. Surface analysis of the nanoparticles was performed by $\mathrm{N}_{2}$ adsorption-desorption isotherm curves. Brunauer-EmmettTeller (BET) surface areas were calculated by the BET method and the pore size distribution was calculated by the Barrett-Joyner-Halenda (BJH) method deduced from desorption data (Quadrasorb-evo, Quantachrome Instrument, USA). Transmission electron microscopy (TEM) images were measured with field-emission transmission electron microscopy (JEM-2100, Japan). Ultraviolet-visible (UV-vis) absorption spectra were analyzed by a SHIMADZU (UV-2401PC, Japan). The $\mathrm{pH}$ value was measured with a $\mathrm{pH}$ meter (PHS-3C, Shanghai INESA Scientific Instrument Co. Ltd., China).

\subsection{Preparation of mesoporous silica nanoparticles (MSNs)}

Mesoporous silica nanoparticles were prepared by sol-gel method [31]. Briefly, a certain amount of CTAB and $0.28 \mathrm{~g} \mathrm{NaOH}$ was dissolved in $480 \mathrm{~mL}$ deionized water. Then pore-expanding agent $7.0 \mathrm{~mL}$ mesitylene was added to the solution. The mixture was stirred vigorously and heated to $80^{\circ} \mathrm{C}$. Afterwards, $5.0 \mathrm{~mL}$ TEOS was added dropwise at a proper rate to the solution. The reaction mixture was stirred vigorously at $80^{\circ} \mathrm{C}$ for another $2 \mathrm{~h}$. The resulting white precipitate was isolated by filtration, washed with abundant ethanol and dried under vacuum at $100^{\circ} \mathrm{C}$ for $12 \mathrm{~h}$.

The structure-templating CTAB and mesitylene molecules were removed from the composite material via solvent extraction. A suspension of $1.0 \mathrm{~g}$ of the as synthesized material was stirred for $5 \mathrm{~h}$ at $60^{\circ} \mathrm{C}$ in a $150 \mathrm{~mL}$ ethanol solution with $0.4 \mathrm{~g} \mathrm{NH}_{4} \mathrm{NO}_{3}$ adding in. The template-removed nanoparticles were then isolated via filtration and dried under vacuum at room temperature.

\subsection{Loading IBU into MSNs (MSN/IBU)}

$0.5 \mathrm{~g}$ MSNs were added to $30 \mathrm{~mL}$ IBU $\mathrm{n}$-hexane solution $(40 \mathrm{mg} / \mathrm{mL})$. Then the mixture was stirred at room temperature for two days. After that, MSN/ IBU was centrifuged and the resulting supernatant was analyzed by using UV-vis spectrophotometry at a $\lambda_{\max }$ of $264 \mathrm{~nm}$ to evaluate the absorbed IBU into MSNs.

\subsection{Chitosan wrapping MSN/IBU (CS/MSN/IBU)}

$0.2,0.4,0.6 \mathrm{~W} / \mathrm{V} \mathrm{CS} /$ acetic acid $(10 \% \mathrm{~V} / \mathrm{V})$ aqueous solution was prepared and the $\mathrm{pH}$ was adjusted to 6.0 with $1 \mathrm{M} \mathrm{NaOH}$. Then $0.2 \mathrm{~g}$ MSN/IBU were added to $40 \mathrm{~mL}$ CS/acetic acid aqueous solution and stirred for $36 \mathrm{~h}$ at room temperature. The mixture was centrifuged, washed with deionized water twice and dried under vacuum at room temperature.

\subsection{In vitro release of IBU}

The in vitro release of IBU was measured by preparing equal weight $\mathrm{MSN} / \mathrm{IBU}$ and $\mathrm{CS} / \mathrm{MSN} / \mathrm{IBU}$ in pH 6.8 and pH 7.4 PBS buffer solutions at concen- 
tration of $4 \mathrm{mg} / \mathrm{mL}$. The mixture was keeping stirred at rate of $30 \mathrm{r} / \mathrm{min}$ and releasing temperature was kept at $37^{\circ} \mathrm{C}$. Then release was determined by taking $3 \mathrm{~mL}$ of the IBU release medium for UV-vis analysis at $1 \mathrm{~h}$ intervals and replaced with the same volume of fresh PBS buffer solutions, which were preheated to $37^{\circ} \mathrm{C}$.

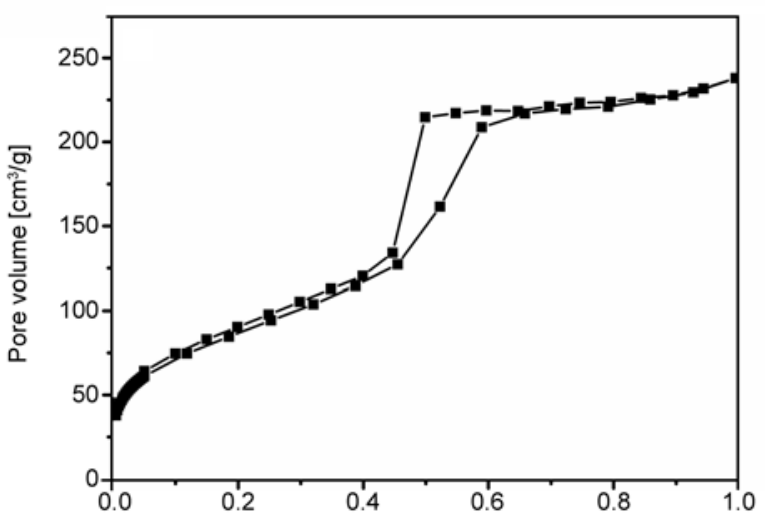

a)

Relative pressure $\left[\mathrm{P} / \mathrm{P}_{0}\right]$

\section{Results and discussion}

\subsection{Morphologies and structures of MSNs} and $\mathrm{CS} / \mathrm{MSN} / \mathrm{IBU}$

In this study, four kinds of MSNs were prepared via different concentrations of CTAB (Figures 1-4, Table 1). When concentration of CTAB was $5.7 \mathrm{mM}$, the prepared MSN had the larger pore volume and

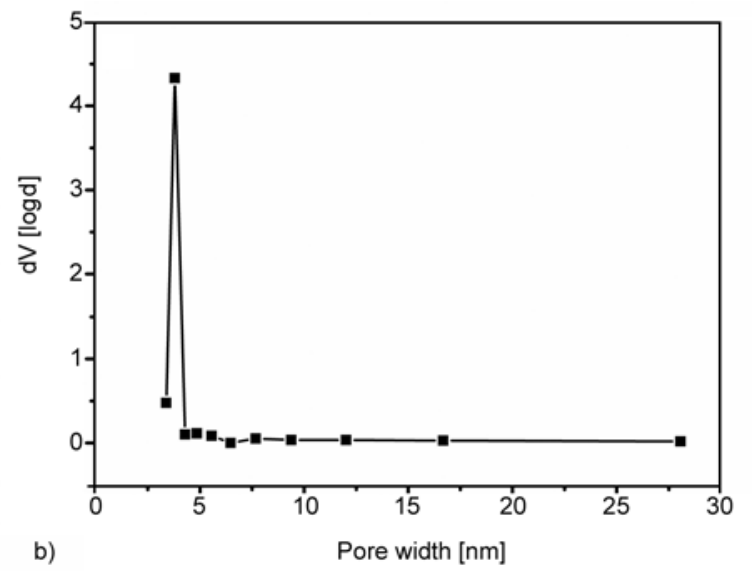

Figure 1. $\mathrm{N}_{2}$ adsorption-desorption isotherms of mesoporous silica (a) and pore size distribution (b), (Concentration of CTAB is $1.9 \mathrm{mM}$ )
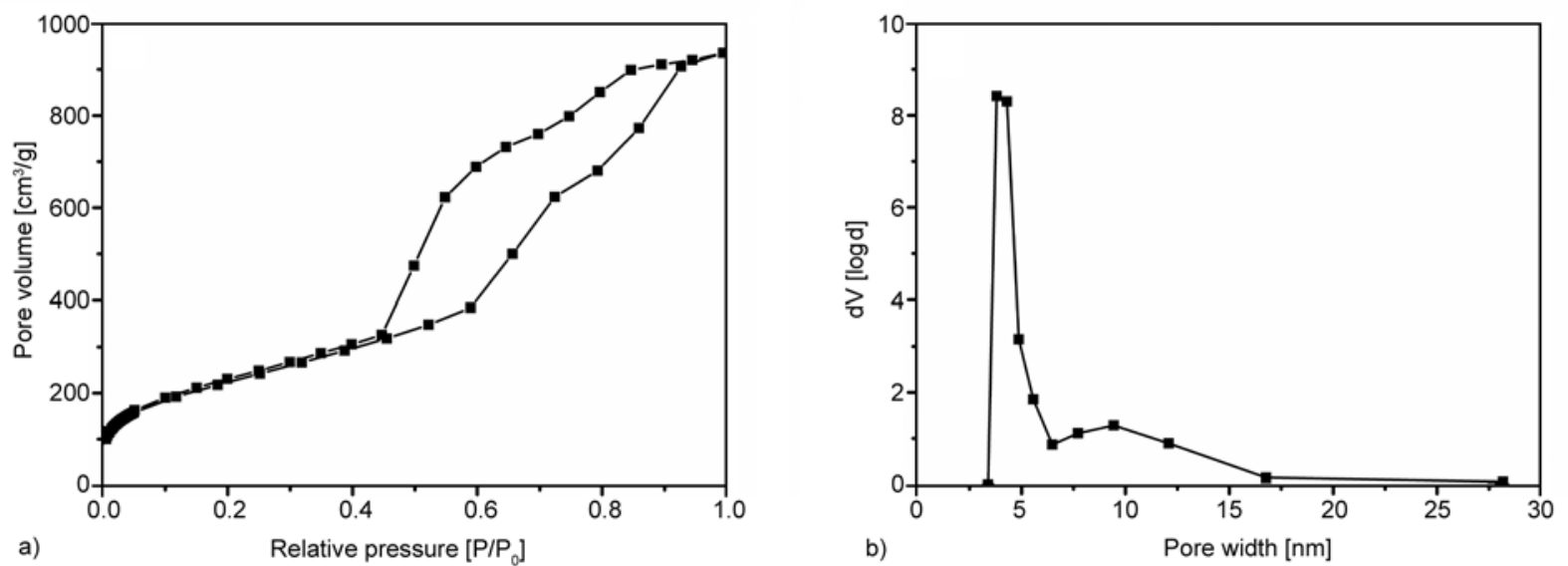

Figure 2. $\mathrm{N}_{2}$ adsorption-desorption isotherms of mesoporous silica (a) and pore size distribution (b), (Concentration of CTAB is $3.8 \mathrm{mM}$ )
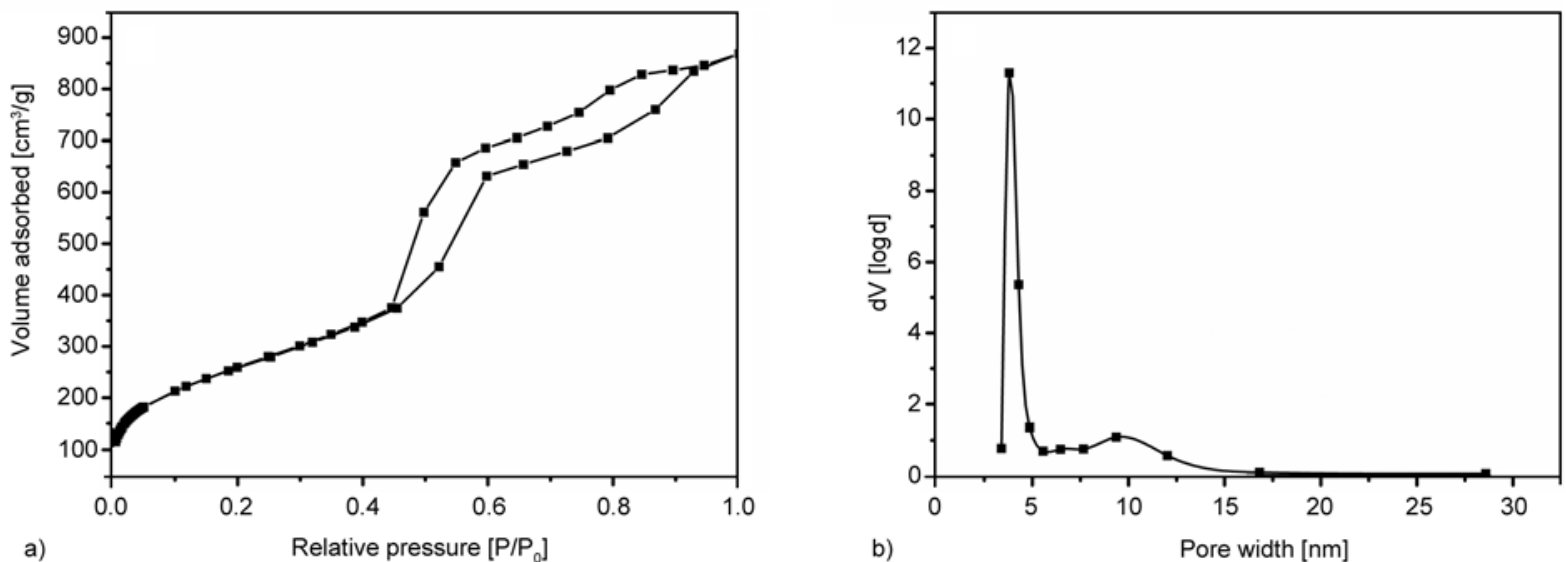

Figure 3. $\mathrm{N}_{2}$ adsorption-desorption isotherms of mesoporous silica (a) and pore size distribution (b), (Concentration of CTAB is $5.7 \mathrm{mM}$ ) 

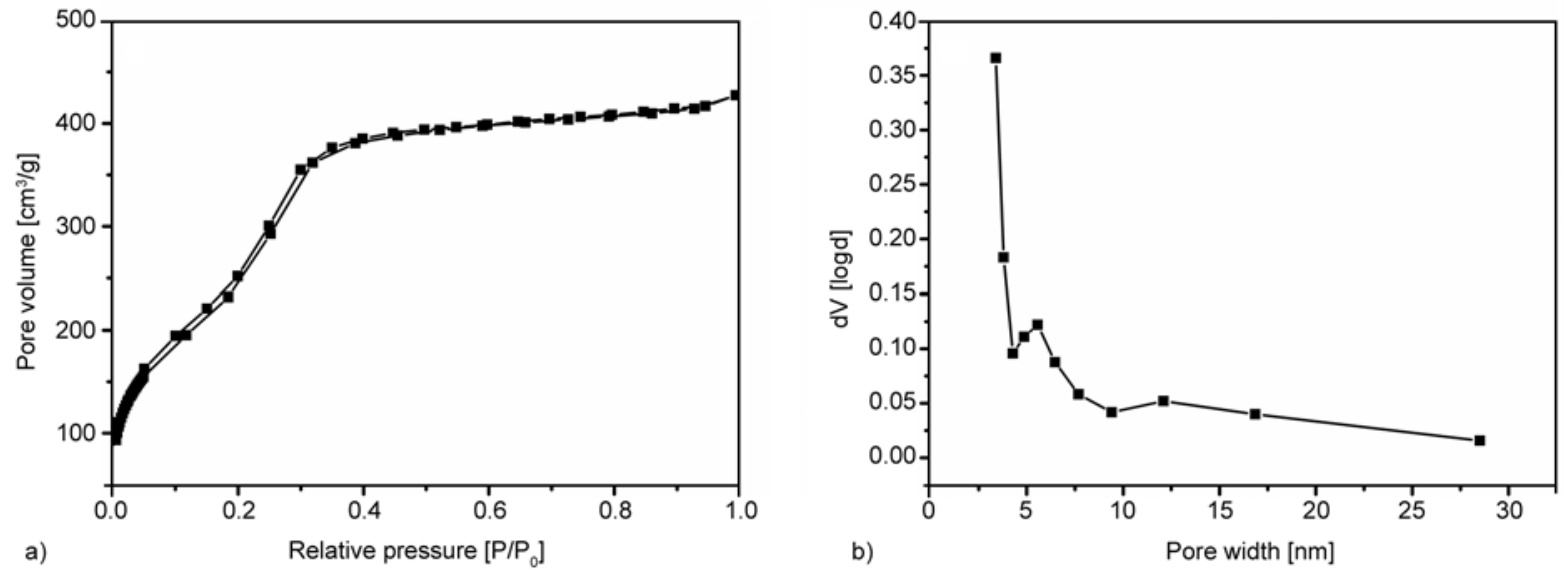

Figure 4. $\mathrm{N}_{2}$ adsorption-desorption isotherms of mesoporous silica (a) and pore size distribution (b), (Concentration of CTAB is $7.6 \mathrm{mM}$ )

Table 1. Structure parameters of MSN and MSN/IBU

\begin{tabular}{|l|c|c|c|c|c|}
\hline \multicolumn{1}{|c|}{ Samples } & $\begin{array}{c}\text { Concentration of CTAB } \\
{[\mathbf{m M}]}\end{array}$ & $\begin{array}{c}\text { BET surface area } \\
{\left[\mathbf{m}^{\mathbf{2}} \mathbf{/ g}\right]}\end{array}$ & $\begin{array}{c}\text { Pore volume } \\
{\left[\mathbf{c m}^{\mathbf{3}} \mathbf{g}\right]}\end{array}$ & $\begin{array}{c}\text { Small mean pore } \\
{[\mathbf{n m}]}\end{array}$ & $\begin{array}{c}\text { Large mean pore } \\
{[\mathbf{n m}]}\end{array}$ \\
\hline MSN1 & 1.9 & 267.1 & 0.29 & 3.8 & 9.3 \\
\hline MSN2 & 3.8 & 818.2 & 1.61 & 3.8 & 9.3 \\
\hline MSN3 & 5.7 & 948.1 & 1.34 & 3.8 & 9.8 \\
\hline MSN4 & 7.6 & 991.1 & 0.09 & 3.4 & 9.8 \\
\hline MSN/IBU & 5.7 & 282.1 & 0.34 & 3.8 & 9.5 \\
\hline
\end{tabular}

BET surface area. So in this study we chose MSN3 as drug nanocarrier. Figure 5 showed the average diameter of the prepared MSN was $200 \mathrm{~nm}$. The MSN had regular array of mesoporous channels and large enough pores to load IBU inside. The TEM image of the chitosan wrapped MSN confirmed that chitosan successfully wrapped on the surface of MSN and CS/MSN/IBU still showed regular spherical structure.

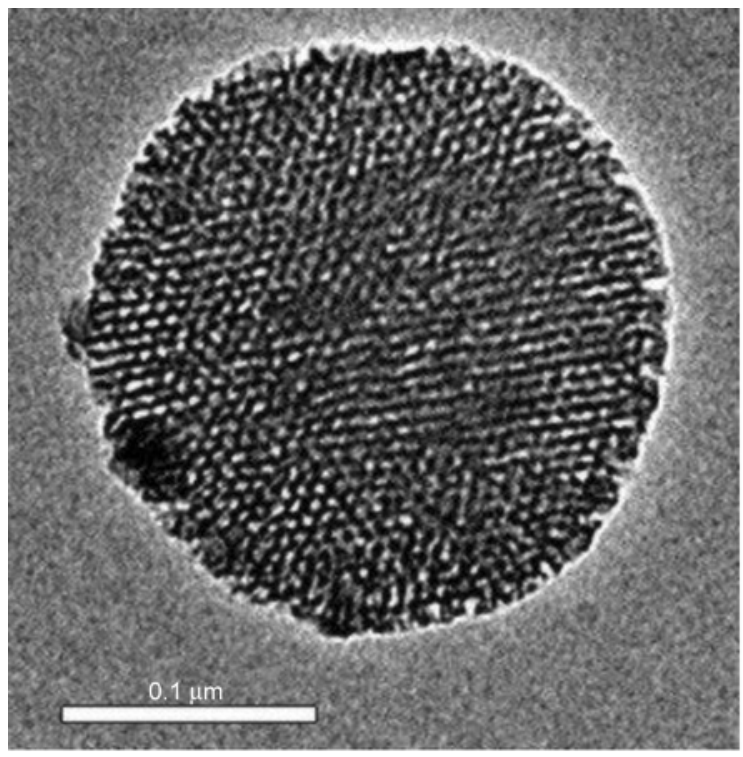

a)

Figure 5. TEM images of MSN (a) and CS/MSN/IBU (b)
As the concentration of CTAB increases, the size of the micelles formed in the solution became larger. CTAB might have been partially adsorbed inside the silica channel, with the result that template was not removed completely in the final and the BET surface area and pore volume decreased sharply.

The $\mathrm{N}_{2}$ adsorption-desorption isotherm curve of MSN showed a typical IV isotherm curve. The BET surface area is $948.1 \mathrm{~m}^{2} / \mathrm{g}$ and pore volume is

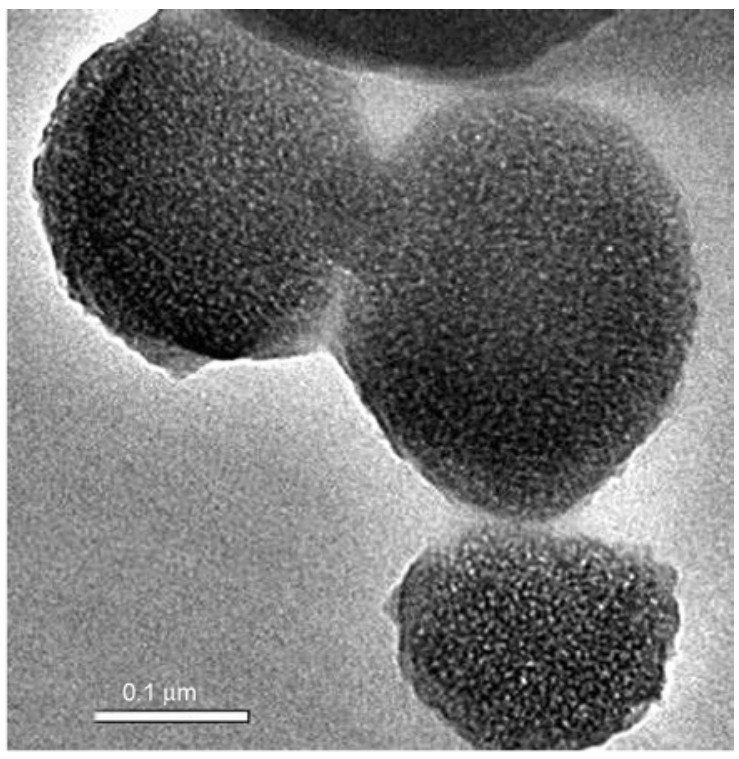

b) 


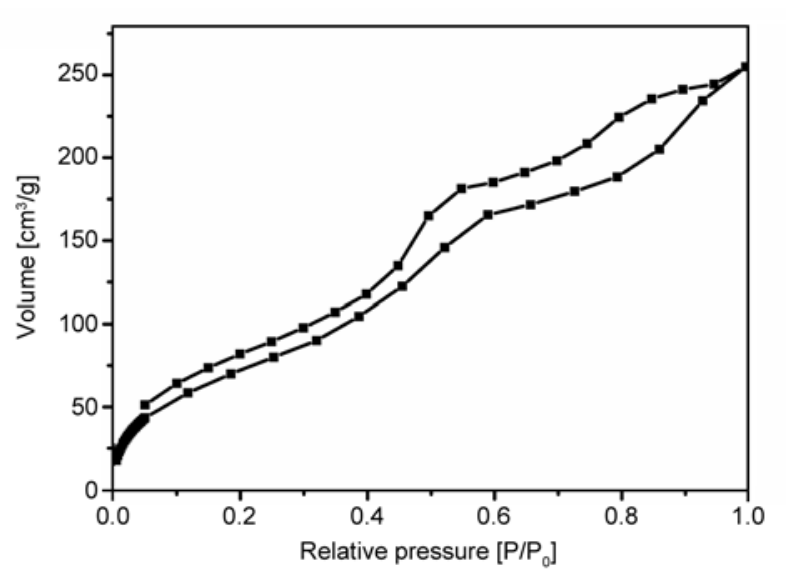

Figure 6. $\mathrm{N}_{2}$ adsorption-desorption isotherm curve of MSN/ IBU

$1.34 \mathrm{~cm}^{3} / \mathrm{g}$ for MSN3 (Figure 3a, Table 1). The BJH method showed two pore size distributions centered on $3.8 \mathrm{~nm}$ (major) and $9.8 \mathrm{~nm}$ (minor) (Figure $3 \mathrm{~b}$, Table 1).

The structures of the nanoparticles were characterized by FTIR. As shown in Figure 7, the FTIR spectrums of MSN, MSN/IBU and CS/MSN/IBU show a hydroxyl absorption peak at $1636 \mathrm{~cm}^{-1}$. And the typical absorption peaks at 1088 and $797 \mathrm{~cm}^{-1}$ were the stretching vibration of $\mathrm{Si}-\mathrm{O}-\mathrm{Si}$ and $\mathrm{Si}-\mathrm{O}$ [28]. While the adsorption spectrums of IBU, MSN/IBU, CS/MSN/IBU all showed the typical absorption peaks of IBU, which were the stretching vibration of $\mathrm{C}=\mathrm{O}$ at $1710 \mathrm{~cm}^{-1}, \mathrm{C}=\mathrm{C}$ vibration and $\mathrm{C}-\mathrm{H}$ of phenyl ring at 1510 and $1420 \mathrm{~cm}^{-1}$, respectively. In addition, both the adsorption spectrums of CS and $\mathrm{CS} / \mathrm{MSN} / \mathrm{IBU}$ had the absorption peaks of amide I at $1652 \mathrm{~cm}^{-1}$ and amide II at $1560 \mathrm{~cm}^{-1}$. Carboxyl groups in IBU molecular and amino groups in CS

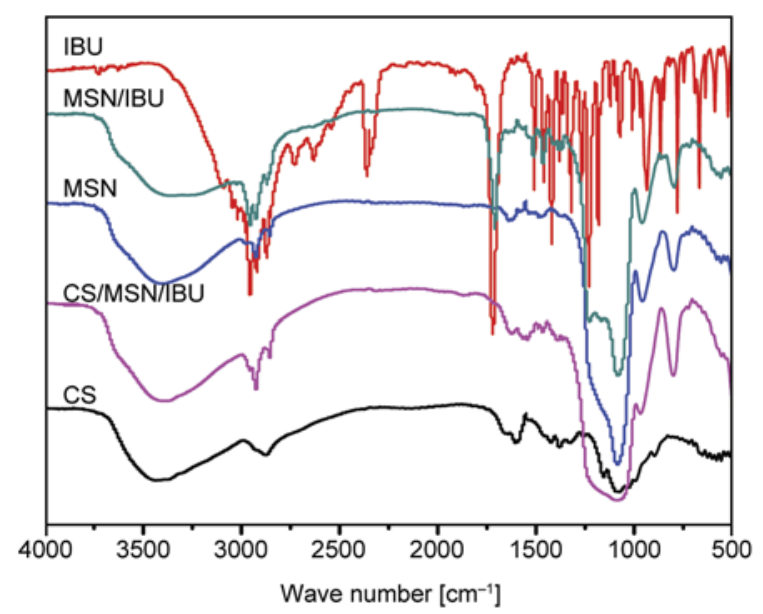

Figure 7. FTIR spectra of CS, IBU, MSN, MSN/IBU, CS/ MSN/IBU molecular interacted together during the preparation process of CS/MSN/IBU, so the characteristic peak $\left(1710 \mathrm{~cm}^{-1}\right)$ did not appear any more. All these results proved that the IBU loaded in MSN and the CS wrapped MSN/IBU successfully. Furthermore, the loading of IBU into the pores of MSN could be demonstrated through $\mathrm{N}_{2}$ adsorption-desorption analysis, which the BET surface area reduced from 948.1 to $282.1 \mathrm{~m}^{2} / \mathrm{g}$ and the pore volume reduced from 1.4 to $0.34 \mathrm{~cm}^{3} / \mathrm{g}$ after IBU loading into MSN (Figure 6, Table 1).

The loading efficiency of IBU into CS/MSN/IBU was dependent on the mass fraction of CS. In the meantime, the loading efficiency could be calculated by weighing method and ultra-violet photometer. The loading efficiency of MSN/IBU ( $\left.L E_{\mathrm{MSN}}\right)$ was deduced from Equation (1). The result was about $52.8 \%$ :

$L E_{\mathrm{MSN}}=\frac{m_{1}-m_{0}}{m_{1}}$

where $m_{0}$ and $m_{1}$ mean the weight of MSN before and after loading IBU into MSN, respectively.

In the process of CS wrapping MSN/IBU, there was IBU leaking out from the channels of MSN. The leaked IBU was measured by ultra-violet photometer (Figure 8). Equation (2) was used to calculate the loading efficiency of CS/MSN/IBU

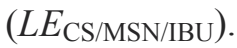

$L E_{\mathrm{CS} / \mathrm{MSN} / \mathrm{IBU}}=\frac{L E_{\mathrm{MSN}} \cdot m_{\mathrm{MSN} / \mathrm{IBU}}-m_{\mathrm{IIBU}}}{m_{\mathrm{CS} / \mathrm{NSN} / \mathrm{IBU}}}$

where $m_{\mathrm{MSN} / \mathrm{BBU}}$ and $m_{\mathrm{IIBU}}$ mean the weight of MSN/ IBU and the weight of IBU leaked from the channels of MSN during the wrapping process.

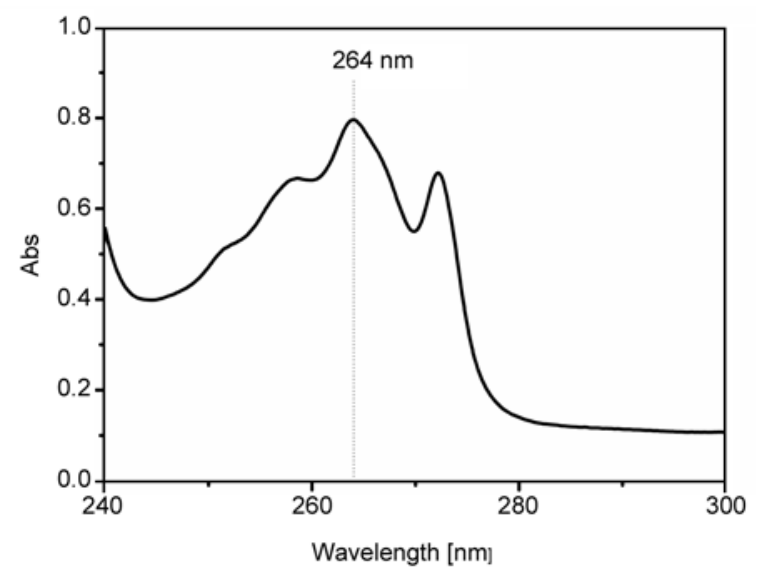

Figure 8. Ultraviolet-visible spectrum of the released IBU during the CS wrapping process 
The loading efficiency of IBU into CS/MSN/IBU was $22.2,28.9,38.3 \%$ respectively when the mass fraction of CS was $0.2,0.4,0.6 \%$.

\subsection{Release behavior of IBU}

The absorption peak at $264 \mathrm{~nm}(A b s)$ of IBU was used as signal to study the release of IBU from $\mathrm{MSN} / \mathrm{IBU}$ and $\mathrm{CS} / \mathrm{MSN} / \mathrm{IBU}$ at $37^{\circ} \mathrm{C}$. The experiments were carried out in PBS buffer solutions at two different $\mathrm{pH}$ values (7.4 and 6.8), which were chosen to mimic the normal body fluid and cancer cell. As shown in Figure 9, the total amount of IBU released from MSN/IBU was about 85 and $93 \%$ at pH 7.4 and 6.8, respectively. The amount of IBU released from CS/MSN/IBU at $\mathrm{pH} 7.4$ was about $9.8 \%$ for $1 \mathrm{~h}$ and $13 \%$ for $12 \mathrm{~h}$, but the release amount had little increase during the whole release process. It indicated that chitosan wrapped MSN/ IBU was stable for a long time and had lower side effect at physiological $\mathrm{pH}$. While at $\mathrm{pH} 6.8$, the release amount increased obviously (30\% for $1 \mathrm{~h}$ and 53\% for $12 \mathrm{~h}$ ) and changed dramatically with the $\mathrm{pH}$ comparing with MSN/IBU. This phenomenon was caused by the change of molecular chain conformation of chitosan. Conformation of chitosan in solution is generally divided into spherical, random coil and rigid rod. One of the main factors influencing conformation is just the $\mathrm{pH}$ [32]. In acidic solution, the amino groups $\left(-\mathrm{NH}_{2}\right)$ on chitosan are protonated into $-\mathrm{NH}^{3+}$, electrostatic repulsion becomes strong between chitosan molecules and the hydrogen bonding becomes less effective. In this case, the molecular chain of chitosan turns into a swollen polymeric matrix which is like loose random coil,

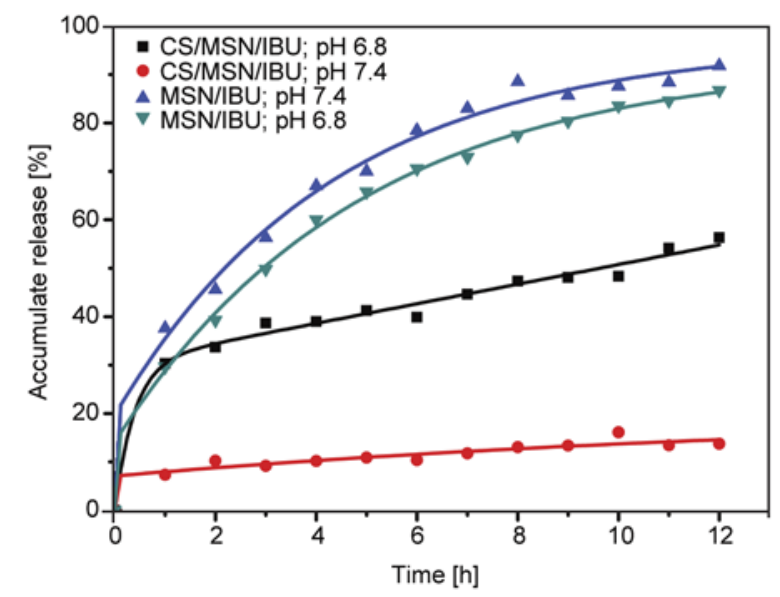

Figure 9. Release profiles of IBU from MSN/IBU and CS/ MSN/IBU drug delivery systems

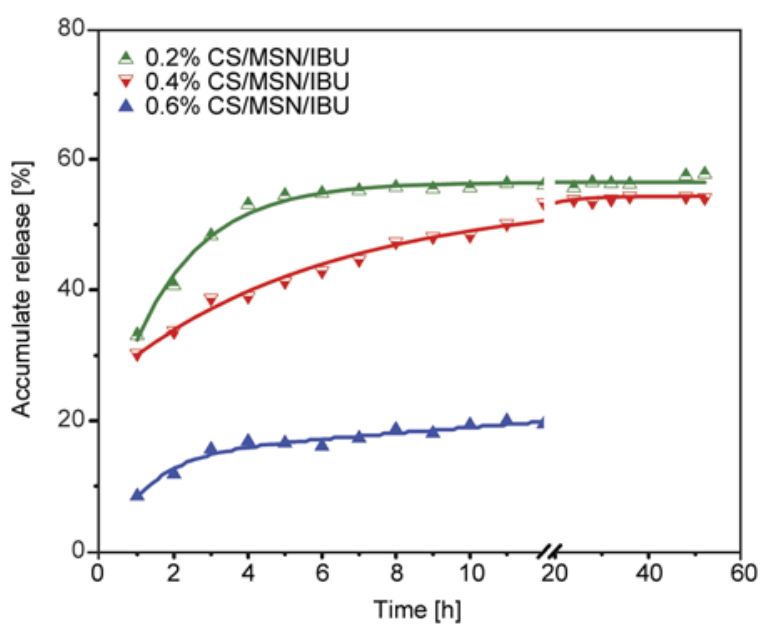

Figure 10. Release profiles of IBU from CS/MSN/IBU with different chitosan mass ratio ( $\mathrm{pH}$ 6.8)

which has less influence on the release of IBU. While at $\mathrm{pH} 7.4$, the amino groups don't carry charge and weaker electrostatic repulsion exists, so the molecular chain gets together as a shrinking mode [10]. This structure blocks the release of IBU to some extent. So the release amount at $\mathrm{pH} 6.8$ was higher than at $\mathrm{pH} 7.4$.

As shown in Figure 10, with the increase of mass fraction of chitosan, the accumulated release amount of CS/MSN/IBU decreased greatly from 56 to $19 \%$. With the increase of mass fraction of CS, solution viscosity increased, which resulted in the structure of $\mathrm{CS} / \mathrm{MSN} / \mathrm{IBU}$ becoming more closely, crosslinking degree increasing and the swelling capacity reducing. Eventually the drug release rate decreased with the increase of mass fraction of CS.

As shown in Figure 11, MSNs were wrapped by chitosan and chitosan presented different states under different $\mathrm{pH}$ conditions because of protonation [10]. In this system, chitosan acted as a $\mathrm{pH}-$ responsive 'gatekeeper' ensuring more drug release at $\mathrm{pH} 6.8$, which was probably due to the formation of hydrogen bond between the $-\mathrm{OH}$ on the MSN and the $-\mathrm{NH}_{2}$ on the chitosan molecule.

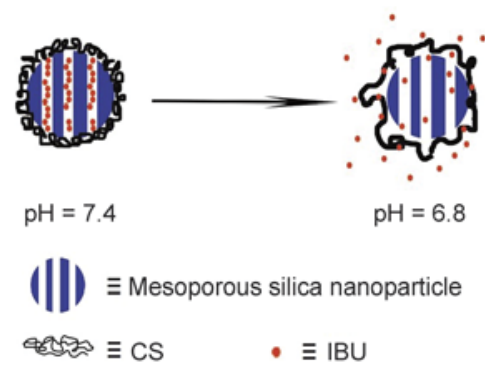

Figure 11. The pH-responsive drug delivery system 


\section{Conclusions}

In summary, we have developed a simple approach to prepare an intelligent drug controlled delivery system by hydrogen bonding biopolymer as $\mathrm{pH}$ responsive 'gatekeeper' and inorganic nanoparticles as drug carriers. The 'gatekeeper' is biodegradable and nontoxic, which could be directly applied to medical environment. MSNs with largest BET surface area and pore width were chosen as drug carriers which could load more drugs. Drug loading demonstrated that IBU loading increased with the increase of mass fraction of chitosan. In vitro release tests demonstrated that IBU release from MSNs was not $\mathrm{pH}$-responsive, yet drug release from $\mathrm{CS} / \mathrm{MSN}$ was $\mathrm{pH}$-responsive with much higher release amount at $\mathrm{pH} 6.8$ than $\mathrm{pH}$ 7.4.

\section{Acknowledgements}

The authors gratefully acknowledge the financial support of the Scientific Research key project of the Education Department Henan Province (14A430041, 14B430035 and 15A430043) and the Scientific and Technological Projects of Henan Province (142102210488).

\section{References}

[1] Deshpande A., Rhodes C., Shah N., Malick A.: Controlled-release drug delivery systems for prolonged gastric residence: An overview. Drug Development and Industrial Pharmacy, 22, 531-539 (1996).

DOI: $10.3109 / 03639049609108355$

[2] Gupta P., Vermani K., Garg S.: Hydrogels: From controlled release to $\mathrm{pH}$-responsive drug delivery. Drug Discovery Today, 7, 569-579 (2002).

DOI: 10.1016/S1359-6446(02)02255-9

[3] Freiberg S., Zhu X. X.: Polymer microspheres for controlled drug release. International Journal of Pharmaceutics, 282, 1-18 (2004).

DOI: $10.1016 /$ j.ijpharm.2004.04.013

[4] He Q., Shi J.: Mesoporous silica nanoparticle based nano drug delivery systems: Synthesis, controlled drug release and delivery, pharmacokinetics and biocompatibility. Journal of Materials Chemistry, 21, 58455855 (2011).

DOI: 10.1039/C0JM03851B

[5] Mitra S., Gaur U., Ghosh P. C., Maitra A. N.: Tumour targeted delivery of encapsulated dextran-doxorubicin conjugate using chitosan nanoparticles as carrier. Journal of Controlled Release, 74, 317-323 (2001). DOI: 10.1016/S0168-3659(01)00342-X

[6] Chou J., Ito T., Bishop D., Otsuka M., Ben-Nissan B., Milthorpe B.: Controlled release of simvastatin from biomimetic $\beta$-TCP drug delivery system. PloS One, 8 , e54676/1-e54676/6 (2013).

DOI: $\underline{10.1371 / \text { journal.pone.0054676 }}$
[7] Cui L., Wang R., Ji X., Hu M., Wang B., Liu J.: Template-assisted synthesis of biodegradable and $\mathrm{pH}$ responsive polymer capsules via RAFT polymerization for controlled drug release. Materials Chemistry and Physics, 148, 87-95 (2014).

DOI: 10.1016/j.matchemphys.2014.07.016

[8] Cui L., Lin H., Guo W., Xiang D., Zhou D., Zhang T., Qu F.: A novel pH-responsive controlled release system based on mesoporous silica coated with hydroxyapatite. Journal of Sol-Gel Science and Technology, 72, 106-113 (2014).

DOI: $10.1007 /$ s10971-014-3419-0

[9] Wang H., Xu F., Li D., Liu X., Jin Q., Ji J.: Bioinspired phospholipid polymer prodrug as a $\mathrm{pH}$-responsive drug delivery system for cancer therapy. Polymer Chemistry, 4, 2004-2010 (2013).

DOI: $10.1039 / \mathrm{C} 2 \mathrm{PY} 20981 \mathrm{~K}$

[10] Popat A., Liu J., Lu G. Q. (M.), Qiao S. Z.: A pHresponsive drug delivery system based on chitosan coated mesoporous silica nanoparticles. Journal of Materials Chemistry, 22, 11173-11178 (2012). DOI: $10.1039 / \mathrm{C} 2 \mathrm{JM} 30501 \mathrm{~A}$

[11] Zhao Y., Vivero-Escoto J. L., Slowing I. I., Trewyn B. G., Lin V. S-Y.: Capped mesoporous silica nanoparticles as stimuli-responsive controlled release systems for intracellular drug/gene delivery. Expert Opinion on Drug Delivery, 7, 1013-1029 (2010).

DOI: $10.1517 / 17425247.2010 .498816$

[12] Yuan L., Tang Q., Yang D., Zhang J. Z., Zhang F., Hu J.: Preparation of $\mathrm{pH}$-responsive mesoporous silica nanoparticles and their application in controlled drug delivery. The Journal of Physical Chemistry C, 115, 9926-9932 (2011).

DOI: $10.1021 / \mathrm{jp} 201053 \mathrm{~d}$

[13] Du J-Z., Du X-J., Mao C-Q., Wang J.: Tailor-made dual $\mathrm{pH}$-sensitive polymer-doxorubicin nanoparticles for efficient anticancer drug delivery. Journal of the American Chemical Society, 133, 17560-17563 (2011). DOI: $10.1021 / \mathrm{ja207150 \textrm {n }}$

[14] Agnihotri S. A., Mallikarjuna N. N., Aminabhavi T. M.: Recent advances on chitosan-based micro- and nanoparticles in drug delivery. Journal of Controlled Release, 100, 5-28 (2004).

DOI: $10.1016 /$ j.jconrel.2004.08.010

[15] Soppimath K. S., Aminabhavi T. M., Kulkarni A. R., Rudzinski W. E.: Biodegradable polymeric nanoparticles as drug delivery devices. Journal of Controlled Release, 70, 1-20 (2001). DOI: 10.1016/S0168-3659(00)00339-4

[16] Vandelli M., Rivasi F., Guerra P., Forni F., Arletti R.: Gelatin microspheres crosslinked with D,L-glyceraldehyde as a potential drug delivery system: Preparation, characterisation, in vitro and in vivo studies. International Journal of Pharmaceutics, 215, 175-184 (2001). DOI: $10.1016 / \mathrm{S} 0378-5173(00) 00681-5$ 
[17] Coombes A. G. A., Rizzi S. C., Williamson M., Barralet J. E., Downes S., Wallace W. A.: Precipitation casting of polycaprolactone for applications in tissue engineering and drug delivery. Biomaterials, 25, 315-325 (2004).

DOI: 10.1016/S0142-9612(03)00535-0

[18] Kumari A., Yadav S. K., Yadav S. C.: Biodegradable polymeric nanoparticles based drug delivery systems. Colloids and Surfaces B: Biointerfaces, 75, 1-18 (2010). DOI: $10.1016 /$ j.colsurfb.2009.09.001

[19] Slowing I. I., Trewyn B. G., Giri S., Lin V. S-Y.: Mesoporous silica nanoparticles for drug delivery and biosensing applications. Advanced Functional Materials, 17, 1225-1236 (2007).

DOI: $10.1002 / \mathrm{adfm} .200601191$

[20] Chen F-H., Zhang L-M., Chen Q-T., Zhang Y., Zhang Z-J.: Synthesis of a novel magnetic drug delivery system composed of doxorubicin-conjugated $\mathrm{Fe}_{3} \mathrm{O}_{4}$ nanoparticle cores and a PEG-functionalized porous silica shell. Chemical Communications, 46, 8633-8635 (2010). DOI: $10.1039 / \mathrm{c} 0 \mathrm{cc} 02577 \mathrm{a}$

[21] Liu Z., Tabakman S., Welsher K., Dai H.: Carbon nanotubes in biology and medicine: In vitro and in vivo detection, imaging and drug delivery. Nano Research, 2, 85-120 (2009).

DOI: $10.1007 / \mathrm{s} 12274-009-9009-8$

[22] Gao X., Cui Y., Levenson R. M., Chung L. W. K., Nie $\mathrm{S}$.: In vivo cancer targeting and imaging with semiconductor quantum dots. Nature Biotechnology, 22, 969976 (2004).

DOI: $10.1038 /$ nbt994

[23] Singh N., Karambelkar A., Gu L., Lin K., Miller J. S., Chen C. S., Sailor M. J., Bhatia S. N.: Bioresponsive mesoporous silica nanoparticles for triggered drug release. Journal of the American Chemical Society, 133, 19582-19585 (2011).

DOI: $10.1021 /$ ja206998x

[24] Slowing I. I., Vivero-Escoto J. L., Trewyn B. G., Lin V. S-Y.: Mesoporous silica nanoparticles: Structural design and applications. Journal of Materials Chemistry, 20, 7924-7937 (2010).

DOI: $10.1039 / \mathrm{c} 0 \mathrm{jm} 00554 \mathrm{a}$
[25] Mitoraj D., Kisch H.: The nature of nitrogen-modified titanium dioxide photocatalysts active in visible light. Angewandte Chemie International Edition, 47, 99759978 (2008). DOI: 10.1002 /anie.200800304

[26] Croissant J., Cattoën X., Man M. W. C., Gallud A., Raehm L., Trens P., Maynadier M., Durand J-O.: Biodegradable ethylene-bis(propyl)disulfide-based periodic mesoporous organosilica nanorods and nanospheres for efficient in-vitro drug delivery. Advanced Materials, 26, 6174-6180 (2014).

DOI: 10.1002/adma.201401931

[27] Chang J-S., Chang K. L. B., Hwang D-F., Kong Z-L.: In vitro cytotoxicitiy of silica nanoparticles at high concentrations strongly depends on the metabolic activity type of the cell line. Environmental Science and Technology, 41, 2064-2068 (2007).

DOI: $10.1021 / \mathrm{es} 062347 \mathrm{t}$

[28] Pourjavadi A., Tehrani Z. M.: Mesoporous silica nanoparticles (MCM-41) coated PEGylated chitosan as a $\mathrm{pH}-$ responsive nanocarrier for triggered release of erythromycin. International Journal of Polymeric Materials and Polymeric Biomaterials, 63, 692-697 (2014). DOI: $10.1080 / 00914037.2013 .862534$

[29] Li L-L., Zhang R., Yin L., Zheng K., Qin W., Selvin P. R., Lu Y.: Biomimetic surface engineering of lanthanide-doped upconversion nanoparticles as versatile bioprobes. Angewandte Chemie, 124, 6225-6229 (2012). DOI: 10.1002/ange.201109156

[30] Liu Z., Jiao Y., Wang Y., Zhou C., Zhang Z.: Polysaccharides-based nanoparticles as drug delivery systems. Advanced Drug Delivery Reviews, 60, 1650-1662 (2008).

DOI: 10.1016/j.addr.2008.09.001

[31] Slowing I. I., Trewyn B. G., Lin V. S-Y.: Mesoporous silica nanoparticles for intracellular delivery of membrane-impermeable proteins. Journal of the American Chemical Society, 129, 8845-8849 (2007). DOI: $10.1021 / \mathrm{ja} 0719780$

[32] Sorlier P., Viton C., Domard A.: Relation between solution properties and degree of acetylation of chitosan: Role of aging. Biomacromolecules, 3, 1336-1342 (2002).

DOI: $10.1021 / \mathrm{bm} 0256146$ 